\title{
Cuerpos que hablan
}

\author{
ELVIRA BURGOS DÍAZ \\ Universidad de Zaragoza
}

La filósofa feminista estadounidense Judith Butler dirige con fuerza su pensamiento hacia la discusión de las categorías de género, de sexo y de identidad. Este es un trabajo que Butler va desarrollando desde sus primeros ensayos feministas. En Gender Trouble, su obra más conocida internacionalmente, la formulación de este decisivo tema logra una gran precisión y rigor argumentativo.

La relación entre sexo, género y deseo va a ser dislocada por Butler; pensada de nuevo quebrando el orden tradicional en el que los elementos se hacían encajar de acuerdo con la norma de la coherencia y estabilidad y de la regla de la naturalidad de los sexos y de la práctica de la heterosexualidad. La crítica de Butler incluye, obviamente, también la disputa de formulaciones propias de la teoría feminista. La separación entre sexo y género, que Butler encontraba ya apuntada en El segundo sexo de Simone de Beauvoir, es subrayada en Gender Trouble como punto de arranque del cuestionamiento tanto del binarismo de género, de la idea de que los géneros han de ser dos, como de la naturalidad del sexo mismo. Más allá del apoyo que desde el principio encuentran sus tesis en los textos de Monique Wittig y de Michel Foucault fundamentalmente, las sucesivas y penetrantes interrogaciones que en Gender Trouble se enlazan unas con otras evidencian cómo sus críticas se han ido afianzando progresivamente con la amplitud de sus argumentaciones y con la extensión de sus fuentes de referencia ${ }^{1}$ :

¿Podemos referirnos a un sexo "dado" o a un género "dado" sin investigar primero cómo se da el sexo y/o el género y a través de qué medios? ¿Y qué es el "sexo" a

1 Butler menciona en Gender Trouble, y en relación con su crítica a la naturalidad del sexo, obras procedentes de varios campos de investigación, filosóficos, antropológicos, así como investigaciones del ámbito de la biología y de la historia de la ciencia. Véase, El género en disputa. El feminismo y la subversión de la identidad, México, Paidós, 2001, notas 8, 9 y 10, p. 39; La edición inglesa original es: Gender Trouble. Feminism and the Subversion of Identity, New York and London, Routledge, 1990 (2 edición de 1999), pp. 151-152. 
fin de cuentas? ¿Es natural, anatómico, cromosómico u hormonal, y cómo puede una crítica feminista valorar los discursos científicos que pretenden establecer tales "hechos"? ¿Tiene el sexo una historia? ¿Posee cada sexo una historia diferente, o varias historias? ¿Hay una historia de cómo se estableció la dualidad del sexo, una genealogía que presente las opciones binarias como una construcción variable? ¿Los hechos supuestamente naturales del sexo se producen discursivamente por medio de diversos discursos científicos al servicio de otros intereses políticos y sociales? ${ }^{2}$

El acento interrogativo de estas enunciaciones, contrarias a la idea de la naturalidad del sexo, indican la conveniencia de insistir en la investigación de estas cuestiones que no teniendo un significado claro e inmediato y que no hallando una respuesta directa y única son problemáticas; son problemas que merecen seguir siendo pensados porque en ellos nos va la vida, sin duda. Que estos problemas son vitales, que afectan a las vidas de las personas, es uno de los aspectos que la obra de Butler ha sabido destacar con contundencia.

Nuestro propósito, en este trabajo, es, sin embargo, más modesto. No trataremos de presentar los hilos maestros de la filosofía de Butler sino de acercar su reflexión sobre el tema concreto de la relación entre cuerpo y lenguaje.

\section{LA MATERIALIDAD DE LOS CUERPOS}

En "How Bodies Come to Matter"3, además de en su Bodies that Matter", Butler niega adscribirse al punto de vista del constructivismo radical, insistiendo en que lo que pretende mostrar es cómo la polémica entre el esencialismo y el constructivismo se funda en una paradoja de no fácil superación. Decir, como hace Butler reiteradamente, que no hay materialidad previa que pueda ser accesible al orden discursivo, puesto que si accedemos a ella, a la materialidad, es en tanto que está ya inserta en lo discursivo, no es afirmar que el cuerpo no es nada más que el producto de una construcción. El constructivismo halla aquí un límite. Este límite es el indicado por aquel "lugar" -la denominada materialidad previa; el cuerpo previo- al que la significación discursiva no puede acceder:

2 El género en disputa, op. cit., pp. 39-40 (he modificado ligeramente la traducción castellana); Gender Trouble, op. cit., pp. 6-7.

3 Irene Costera Meijer, and Baukje Prins, "How Bodies come to Matter: An Interview with Judith Butler", en Signs. Journal of Women in Culture and Society, vol. 23, n. ${ }^{\circ}$ 2, 1998.

4 Judith Butler, Bodies that Matter: On the Discursive Limits of 'Sex', New York and London, Routledge, 1993. Traducción española: Cuerpos que importan. Sobre los límites materiales y discursivos del «sexo», Buenos Aires, Paidós, 2002. 
"afirmar que el cuerpo es un referente escurridizo no es lo mismo que afirmar que es sólo y siempre construido. En algún sentido, esto es precisamente afirmar que existe un límite a la construcción, un lugar, por decirlo de alguna manera, donde la construcción necesariamente encuentra su límite"5.

Cierto que Butler, ella misma lo admite, desliza su análisis sobre el cuerpo hacia el campo del lenguaje. El "Prefacio" de Cuerpos que importan se inicia con las siguientes palabras: "Comencé a escribir este libro tratando de considerar la materialidad del cuerpo, pero pronto comprobé que pensar en la materialidad me arrastraba invariablemente a otros terrenos" ${ }^{6}$. Es Igualmente evidente su interés en dejar claro que el cuerpo no se reduce a lenguaje aunque sea compleja la vinculación entre cuerpo y lenguaje.

Uno de los subtítulos contenidos en esta obra de Butler, Bodies that Matter, nos arroja la pregunta: "Los cuerpos, ¿son puramente discursivos?" supuesta materialidad del cuerpo, se nos dice ahí, a la que intentamos referirnos con términos lingüísticos es justo aquello que el lenguaje fracasa en captar pero que insistentemente intenta denotar. Es algo que el lenguaje "demanda" y que en ese sentido tiene que ver con el lenguaje aunque no es de modo estricto una parte del lenguaje. La materialidad formulada en el lenguaje "conservará esa postulación como su condición constitutiva". "La distinción absoluta", prosigue Butler, "entre lenguaje y materialidad que procuraba asegurar la función referencial del lenguaje socava radicalmente esa misma función" $"$, porque el lenguaje no puede indicar a aquello que ha sido postulado como radicalmente exterior a sí mismo. Mas, de aquí no se puede concluir ni que el cuerpo sea exclusivamente una realidad lingüística, como ya ha sido dicho, ni que el cuerpo no tenga que ver con el lenguaje. Materialidad y lenguaje no son, en último término, la misma cosa y, por otro lado, no dejan de estar profundamente imbricados en una mutua interdependencia. Butler dice: "el lenguaje y la materialidad nunca son completamente idénticos ni completamente diferentes".

5 Irene Costera Meijer, and Baukje Prins, "How Bodies come to Matter: An Interview with Judith Butler", op. cit., p. 278 (la traducción es mía).

6 Judith Butler, Cuerpos que importan, op. cit., p. 11; Bodies that Matter, op. cit., p. ix. Butler insistirá en esta idea en obras posteriores como en Excitable Speech. A Politics of the Performative, New York and London, Routledge, 1997 (traducción castellana: Lenguaje, poder e identidad, Madrid, Síntesis, 2004) y también en Undoing Gender, Routledge, New York-London, 2004 (traducción castellana: Deshacer el género, Barcelona, Paidós, 2006). En esta última obra escribe: "There is always a dimension of bodily life that cannot be fully represented, even as it works as the condition and activating condition of language", pp. 198-199.

7 Judith Butler, Cuerpos que importan, op. cit., p. 109; Bodies that Matter, op. cit., p. 67.

8 Judith Butler, Cuerpos que importan, op. cit., p. 109; Bodies that Matter, op. cit., p. 68.

9 Judith Butler, Cuerpos que importan, op. cit., p. 111; Bodies that Matter, op. cit., p. 69. 
Según Veronica Vasterling, un cierto acceso a los fenómenos que no conlleve a la vez su conocimiento o su entendimiento sí es posible. La vivencia fenomenológica del cuerpo es la que la autora considera en este contexto. De acuerdo con la fenomenología, el cuerpo es una materia que persiste y Vasterling relaciona esta concepción del cuerpo con un pasaje del texto de Butler donde se alude a la materialidad del cuerpo como algo que persiste y donde queda especificado que lo que persiste es "una demanda en y por el lenguaje" 10 , algo que requiere ser descrito, explicado, interpretado, analizado. A pesar de que Butler dedica algunos de sus ensayos a la revisión crítica de la orientación fenomenológica ${ }^{11}$, Vasterling, no obstante, detecta cierta aproximación hacia la fenomenología en el fragmento citado de Butler, convirtiendo aquello que persiste como "demanda en y por el lenguaje" en el "cuerpo ininteligible" 12 al que tenemos acceso a través de la experiencia vivida. De este modo, Vasterling replica la tesis que vincula accesibilidad e inteligibilidad, y que ella lee en la obra de Butler como su principal postura epistemológica, mediante un punto de vista fenomenológico ${ }^{13}$ que asimismo, aunque sólo en momentos aislados y más implícita que explícitamente, detecta en Bodies that Matter.

La preocupación por lo abyecto ${ }^{14}$, muy presente en Butler y en concreto en este libro de Cuerpos que importan, no puede por menos que hacernos des-

10 Judith Butler, Cuerpos que importan, op. cit., p. 108; Bodies that Matter, op. cit., p. 67.

11 Véase Judith Butler, "Performative Acts and Gender Constitution: An Essay in Phenomenology and Feminist Theory", en Theatre Journal, 40, invierno de 1988, pp. 519-531. El texto está publicado además en Sue-Ellen Case (ed.), Performing Feminism: Feminist Critical Theory and Theatre, Baltimore, J. Hopkins University Press, 1990. También en Katie Conboy, Nadia Medina, and Sarah Stanbury (eds.), Writing on the Body: Female Embodiment and Feminist Theory, New York, Columbia University Press, 1997, pp. 401-417. Traducción castellana: "Actos performativos y constitución del género: un ensayo sobre fenomenología y teoría feminista", Debate Feminista, no 18, 1998, pp. 296-314. Puede consultarse asimismo el texto de Butler, "Sexual Ideology and Phenomenological Description. A Feminist Critique of Merleau-Ponty's Phenomenology of Perception", en Jeffner Allen and Iris Marion Young (eds.), The Thinking Muse: Feminism and Modern French Philosophy, Bloomington and Indianapolis, Indiana University Press, 1989, pp. 85-100.

12 Veronica Vasterling, "Butler's Sophisticated Constructivism: A Critical Assessment", Hypatia, vol. 14, n 3, Summer 1999, p. 25.

13 En su texto "Body and language: Butler, Merleau-Ponty and Lyotard on the Speaking Embodied Subject", International Journal of Philosophical Studies, vol. 11 (2), 2003, pp. 205223, Vasterling explica más con detalle el punto de vista sobre la relación cuerpo y lenguaje de Merleau-Ponty y lo confronta con la perspectiva de Butler y de Lyotard. Vasterling considera que es mérito de Merleau-Ponty el haber rehabilitado el cuerpo sensible, un cuerpo expresivo e intencional del que depende, y no sólo del lenguaje, lo que vemos y entendemos. Merleau-Ponty, opina Vasterling, da respuesta a cuestiones que en Butler permanecen insatisfechas.

14 El concepto de lo abyecto lo toma Butler de la obra de Julia Kristeva, The Powers of Horror: An Essay on Abjection, New York, Columbia University Press, 1982. Publicada originalmente como Pouvoirs de l’horreur, Paris, Éditions de Seuil, 1980. 
estimar en este punto la crítica de Vasterling. Lo llamado abyecto por Butler es lo rechazado, lo considerado como no significativo, y como no vivible. El cuerpo abyecto sería así un cuerpo no inteligible, un cuerpo que no importa. A ese cuerpo abyecto hay acceso pero no a través de la vivencia fenomenológica pura sino mediante lo discursivo mismo, porque, y aquí está el nudo crucial para rebatir a Vasterling, Butler no da por supuesto el cuerpo abyecto como realidad previamente dada sino que afirma que el carácter de ininteligible, de abyecto, de ese cuerpo está instituido discursivamente. Lo excluido de la significación, lo que Butler llama, siguiendo a Derrida ${ }^{15}$, el ámbito del "exterior constitutivo", no es un "exterior absoluto" sino que está inmanentemente producido por y en el proceso de significación, con lo que tiene capacidad para irrumpir subvirtiendo los límites y las definiciones de las categorías hegemónicas. Ello implica que, por una parte, Butler no identifica sin más accesibilidad e inteligibilidad si bien sí asimila accesibilidad y lenguaje, pero entiéndase que ambas formulaciones no dicen lo mismo puesto que de ese ámbito de lo lingüístico deriva tanto lo inteligible como lo ininteligible, lo que se puede nombrar tanto como lo que no se puede nombrar; $y$, por otra parte, implica que la posibilidad de acción de lo despojado de inteligibilidad no depende de la fenomenológicamente inmediata vivencia corporal. En "How Bodies come to Matter"16, Butler afirma que la abyección es "un proceso discursivo" y afirma, además, que los "discursos habitan en los cuerpos", "son parte de su propia sangre vital"; no podemos considerar, entonces, que el proceso discursivo transcurre por un camino y el cuerpo vivido por otro distinto.

Mas, que el cuerpo, como el sexo y el género, ha de ser pensado desde el ángulo de las elaboraciones discursivas remite al núcleo central de la teoría de Butler que se expresa bajo el concepto de performatividad.

15 Butler se refiere a la obra de Jacques Derrida, Positions, Chicago, University of Chicago, 1978, traducida al castellano como Posiciones, Valencia, Pre-Textos, 1977.

16 "How Bodies come to Matter", op. cit., p. 282. Es muy interesante, además, retener de esta entrevista cómo defiende Butler su tendencia teórica a ser cautelosa a la hora de proporcionar ejemplos concretos que puedan aclarar sus posiciones. El peligro que encierran los ejemplos es que pueden acabar por convertirse en normativos, cerrando el significado de los términos para otros usos útiles no previstos todavía. Sin embargo, Butler desciende a dar alguna imagen más concreta sobre qué entiende por abyecto. Lo abyecto, nos dice, no sólo tiene que ver con cuerpos cuyos sexos, géneros, sexualidades están fuera de la norma hegemónica; también alude a cuerpos y vidas que son rechazados por su piel, raza, etnia, religión, cultura, entre otras posibilidades. En Estados Unidos, precisa aún más, las vidas no occidentales son, en muchos casos, consideradas abyectas. 


\section{LA PERFORMATIVIDAD DE LOS ACTOS DE HABLA}

Aunque la noción de performativad recorre el conjunto de la obra de Butler, es en su libro posterior Excitable Speech. A politics of the Performative ${ }^{17}$ donde atiende minuciosamente al modo del trabajo de la performatividad lingüística ${ }^{18}$, centrándose particularmente, en esta ocasión, en los actos de habla y en concreto en los actos de habla que hieren. Que hay actos de habla capaces de causarnos una herida es signo indicativo, claramente, de que somos seres lingüísticamente vulnerables. Y si podemos ser dañados por el lenguaje es porque necesitamos el lenguaje en orden a ser; necesitamos el lenguaje para dotarnos de existencia, para otorgar inteligibilidad a nuestra vida: este es un contundente razonamiento. El nombre que se nos impone al nacer es muestra de ello, el primer signo de que la nuestra es una existencia habitada en el lenguaje.

Incidir en el término herida, en que el lenguaje es capaz de producir una herida, semejante a un instrumento afilado cuya fuerza penetra con dolor la materia orgánica, es otro modo de traer a escena el complejo problema de la relación entre cuerpo y discurso que desde un encuadre diferente había sido tema de estudio en Bodies that Matter.

El lenguaje al que Butler califica con el término inglés de "excitable" es aquel que está "fuera de nuestro control"19. Y, para ella, esta es su hipótesis, en algún sentido el habla es siempre "excitable". Su argumentación a este respecto tiene en cuenta directamente y por extenso la teoría de los actos de habla de Austin, formulada en Cómo hacer cosas con palabras: palabras y acciones ${ }^{20}$; la revisión de las tesis de Austin realizada por Derrida fundamentalmente en

17 Judith Butler, Excitable Speech. A Politics of the Performative, New York \& London, Routledge, 1997. Traducción castellana: Lenguaje, poder e identidad, Madrid, Síntesis, 2004.

18 Pueden consultarse, como estudios de las tesis de Butler de Excitable Speech, mis anteriores trabajos "Habitando en el interior del lenguaje. De las palabras que hieren", Er, Revista de Filosofía, n. ${ }^{\circ}$ 28, 2000, pp. 87-119; Elvira Burgos Díaz y José Luis Aliaga Jiménez, "Estudio Preliminar", en Delia Esther Suardiaz, El sexismo en la lengua española, Zaragoza, Libros Pórtico, 2002. Véase en particular el apartado titulado "Modelos fluidos en el análisis de la interacción lengua-género: las tesis de Judith Butler", pp. 80-85.

19 Judith Butler, Lenguaje, poder e identidad, op. cit., p. 36: "En la ley, los enunciados "que se excitan" son aquellos llevados a cabo bajo coacción, normalmente se trata de confesiones que no pueden utilizarse delante de un tribunal porque no reflejan el equilibrio mental del que las pronuncia. Mi hipótesis es que el habla está siempre de algún modo fuera de control"; Excitable Speech, op. cit., p. 15: "In the law, "excitable" utterances are those made under duress, usually confessions that cannot be used in court because they do not reflect the balanced mental state of the utterer. My presumption is that speech is always in some ways out of our control".

20 John L. Austin, Cómo hacer cosas con palabras: palabras y acciones, Barcelona, Paidós, 1982. La versión inglesa que cita Butler es How to Do Things With Words, Cambridge, Mass, Harvard University Press, 1962. 
"Firma, acontecimiento, contexto" 21 ; y, además, y ocupando un lugar destacable, las reflexiones críticas, también en relación a la obra de Austin, elaboradas por Felman sobre el "cuerpo que habla"22.

En la ya clásica distinción propuesta por Austin entre expresiones constatativas y expresiones realizativas (performative utterances), se precisa que las primeras son afirmaciones en las que algo, un referente objetivo, es descrito. Estas oraciones, de significado estable y universal, son susceptibles de ser sometidas al valor de autoridad de la verdad, de acuerdo con la lógica clásica de oposición entre enunciado verdadero y falso. Las segundas, las expresiones performativas, son aquellas que realizan una acción por medio de las palabras. Estas, indicó Austin, no se rigen por el criterio de verdad dado que no describen algo existente fuera del lenguaje sino que han de ser medidas según el grado de su fuerza y eficacia. Mérito de Austin fue mostrar interés teórico por este tipo de enunciados no descriptivos que desplazan el lugar privilegiado del valor de verdad, y orientar con ello el campo de estudio sobre el lenguaje en una dirección que desde entonces muestra ser claramente fructífera.

En el desarrollo de su teoría, Austin propuso la diferenciación entre tres tipos de dimensiones de los actos lingüísticos: la dimensión locucionaria o acto locucionario, que son expresiones constatativas; la dimensión ilocucionaria o acto ilocucionario, que son no las que realizan meramente el acto de decir algo sino las que además realizan un acto al decir algo, las que producen la realidad que nombran en el acto mismo de nombrarla (prometer, insultar, la declaración de una unión matrimonial); y la dimensión perlocucionaria o acto perlocucionario, que son aquellos efectos que se derivan, no necesariamente de un modo inmediato, del hecho de decir algo, esto es, las consecuencias sobre nuestros sentimientos, comportamientos, acciones, ocasionadas por las palabras emitidas (intimidar, convencer, ofender, alarmar).

La performativad de las palabras, la capacidad para "hacer cosas con palabras", Austin la hizo residir en la fuerza ilocucionaria (illocutionary force). Butler subrayará cómo está implícita en la teoría de Austin la idea de que en

21 Jacques Derrida, "Firma, acontecimiento, contexto", en Márgenes de la filosofía, Madrid, Cátedra, 1989, pp. 347-372. La versión inglesa que cita Butler es "Signature, Event, Context", in Limited Inc., Northwestern University Press, Evanston, 1988, pp. 1-23.

22 Shoshana Felman, The Literary Speech Act: Don Juan with J. L. Austin, or Seduction in Two Languages, Ithaca, Cornell University Press, 1983. El título original de esta obra es Le Scandale du corps parlant: Don Juan avec Austin, ou la séduction en deux langues, Paris, Éditions du Seuil, 1980. La nueva edición de la obra en lengua inglesa ha recuperado en su título el término cuerpo anteriormente omitido: The Scandal of the Speaking Body. Don Juan With J. L. Austin, or Seduction in Two Languages, Stanford, California, Stanford University Press, 2003. En esta segunda edición se ha introducido el texto de Butler "Afterword", pp. 113-123. 
los actos ilocucionarios los efectos se producen sin que transcurra ningún intermedio temporal entre el acto de habla y la acción realizada. Palabra y acción serían así acontecimientos simultáneos ${ }^{23}$. Además, Butler relacionará el acto de habla ilocucionario de Austin con la interpelación althusseriana ${ }^{24}$ en tanto que uno y otra asientan su eficacia en la dimensión convencional, ritual, donde se integran. Si bien, mientras que el sujeto en Austin emite su acto de habla, en Althusser el sujeto es constituido por la llamada de la voz del otro ${ }^{25}$.

"Firma, acontecimiento, contexto" ofrece el replanteamiento derridiano de la performatividad. Observa sobre Austin Derrida el acierto de un enfoque no restringido al ámbito de la lingüística, de la autoridad del código, ni de la semántica, de los usos del lenguaje. Aprecia el carácter "paciente, abierto, aporético" del análisis de Austin, pero, sin embargo, encuentra sobre todo su fecundidad más en "el reconocimiento de sus puntos muertos que en sus posiciones" 26 . A pesar de que en su puesta en cuestión de la validez del criterio de verdad para toda clase de actos lingüísticos abre la posibilidad para una crítica eficaz del idealismo metafísico que privilegia en el lenguaje el significado y la verdad y que mantiene una distinción jerárquica entre un supuesto uso normal y otro anormal del lenguaje, Derrida comenta cómo Austin permanece, no obstante, deudor de la tradición filosófica clásica.

En su empeño por determinar las situaciones de fracaso del performativo, su origen y sus condiciones -lo que supone también un estudio de las circunstancias del éxito del performativo-, Austin conserva la idea de que los contextos son determinables y permanentes y sostiene que la intención del hablante es el soporte de su acto enunciativo. El sujeto hablante comunica en la expresión performativa un sentido intencional aunque su locución no busque un referente en algo exterior. Austin defiende, según Derrida, que el contexto es definible de modo exhaustivo y que el sujeto detenta una conciencia libre y soberana

23 Judith Butler, Lenguaje, poder e identidad, op. cit., p. 39; Excitable Speech, op. cit., p. 17.

24 Véase, Louis Althusser, "Ideology and Ideological State Apparatuses (Notes towards an Investigation)", en Lenin and Philosophy and Other Essays, New York, Monthly Review Press, 1971 (publicado por primera vez en La Pensée, 1970).

25 Véase, Judith Butler, Lenguaje, poder e identidad, op. cit., pp. 49-51; Excitable Speech, op. cit., pp. 24-26. En Lenguaje, poder e identidad, pp. 4-63; Excitable Speech, pp. 24-34, Butler -que ya había reflexionado sobre la tesis de Althusser en Bodies that Matter (Cuerpos que importan)- retoma el análisis de la interpelación de Althusser cuestionando el privilegio de la voz. Butler insiste en defender que la eficacia de la interpelación, que no puede comprenderse bajo el modelo del poder divino-soberano, no se reduce a la voz que enuncia sino que la interpelación debe entenderse también como discurso y de acuerdo con la noción de citacionalidad que muestra que el origen y el fin de la interpelación no pueden determinarse plenamente.

26 Jacques Derrida, "Firma, acontecimiento, contexto", op. cit., p. 363. 
que controla plenamente su habla; un habla donde la presencia de la unidad del sentido no queda quebrada, entonces, por ningún orificio de fuga.

Cuestión problemática, finalmente, es para Derrida que el fracaso del performativo sea pensado por Austin como una interrupción circunstancial del funcionamiento normal del lenguaje ordinario -concebido como un sistema unívoco-; como un riesgo accidental y no como elemento estructural del fenómeno lingüístico. La mirada deconstructiva de Derrida retiene precisamente esto que para Austin es secundario y marginal, la posibilidad del fallo del performativo, como rasgo estructural, como la interna condición de posibilidad del funcionamiento mismo del performativo. Fijándose en las tres circunstancias de enunciación de un performativo, la enunciación en una escena, en un poema o en un soliloquio, mencionadas por Austin como situaciones que por no ser ordinarias conducen a un uso vacío del performativo, afirma Derrida: "Pues, en fin, lo que Austin excluye como anomalía, excepción, "no serio", la cita (en la escena, en un poema, o en un soliloquio), ¿no es la modificación determinada de una citacionalidad general -de una iterabilidad general, más bien- sin la cual no habría siquiera un performativo "exitoso"?"27. Austin, según Derrida, incurre en la paradoja de situar al lenguaje ordinario fuera de esa ley -la interabilidadque define al lenguaje como tal.

El acontecimiento de enunciación ni es puro ni singular; la expresión performativa no podría tener lugar sin ese mecanismo de disolución de la singularidad que es la cita. Para Austin es la cita una excepción en la dinámica de la performatividad, un accidente que ocasiona su fracaso. Para Derrida la citacionalidad e iterabilidad es condición de existencia del performativo y, más aún, del lenguaje en general.

Desde su pensamiento sobre la escritura como différance es en principio desde donde Derrida, en este ensayo sobre la teoría de Austin, postula su concepto de iterabilidad. La escritura requiere en su estructura de esta instancia de la repetición para que logre su carácter de legibilidad: "Esta iterabilidad (iter, de nuevo vendría de itara, "otro" en sánscrito, y todo lo que sigue puede ser leído como la explotación de esta lógica que liga la repetición a la alteridad) estructura la marca de escritura misma" 28 . Este vínculo de repetición y alteridad nombrado en el concepto de iterabilidad -repetición o citacionalidad alterada en cada contexto nuevo- indica que la escritura rompe la lógica metafísica de la necesidad de la presencia (lo que Derrida denomina logocentrismo), esto es, de una autoridad última legitimadora, ya que funciona, y ha de funcionar, en ausencia tanto de todo destinatario determinado como en ausencia asimismo del emisor originario, en ausencia de la conciencia, de la intención del sujeto productor del texto. 
De la iterabilidad subraya Derrida tres consecuencias ${ }^{29}$ : que el signo significante continúa permaneciendo al margen del momento de su surgimiento; que rompe con el contexto de su inscripción: con el marco de vida del escritor, con la intención de su escritura y también con el contexto semiótico interno al texto ya que se puede reescribir o injertar todo sintagma en otro escrito diferente a aquel del que ha sido tomado; y que el signo escrito viene constituido por el espaciamiento que no sólo le posibilita ser extraído de su contexto interno sino que le permite ser separado de todos los referentes, objetivos y subjetivos.

Y lo dicho sobre la escritura se extiende hacia el acto de habla -y a todo lenguaje-. En el performativo, en particular, porque Derrida aprovecha la teoría de Austin, se observa esta estructura de la iterabilidad. Es cuando una fórmula se cita -resulta iterable- según un modelo convencional cuando es reconocible y cuando es entonces capaz de producir el efecto performativo de efectuar un contrato matrimonial, por ejemplo. Derrida puntualiza, sin embargo, que hay diferentes tipos de citacionalidad; que no es exactamente la misma citacionalidad la que se pone en práctica en una obra de teatro que en el desarrollo de un performativo que logra hacer lo que dice. Lo fundamental en este punto es la afirmación de la existencia de una estructura general de iterabilidad que arruina la pretensión de una enunciación entendida como acontecimiento único, singular y original, que gobierna y controla en todos sus aspectos la operación de enunciación.

La oposición entre enunciados singulares y enunciados citacionales no tiene lugar. Desde este óptica "la intención que anima la iteración no estará nunca presente totalmente a sí misma y a su contenido" 30 . Esta ausencia de la intención conlleva además que el contexto de la enunciación no puede ser determinado de modo pleno ya que para ello sería requerible la presencia, actualidad y transparencia de la intención del acto de habla. Hay ciertos efectos de conciencia en el acto performativo, advierte Derrida, pero la deconstrucción de la metafísica occidental implica el desplazamiento de las oposiciones y de sus sistemas de jerarquías; entre ellas, entre las dicotomías que han de ser criticadas, está la oposición entre enunciados-acontecimientos singulares y enunciados citacionales (entre habla y escritura; entre usos normales y usos anormales del lenguaje; entre lo esencial y lo accidental; entre el éxito y el fracaso).

Si Austin privilegia el acto ilocucionario haciendo recaer la fuerza performativa en el poder de la voz, de una voz potente, como un ser divino, para crear lo que dice eliminando toda suerte de efectos imprevistos, Derrida incide en la iterabilidad en tanto motor de la performatividad. Esto supone, además, que en el planteamiento de Derrida las fronteras entre actos ilocucionarios y actos

29 Véase, ibíd., pp. 358-359.

30 Ibíd., p. 368. 
perlocucionarios quedan difuminadas bajo el aliento común de una iterabilidad que es repetición y alteridad.

Esa dimensión del lenguaje de "excitable", de no absolutamente controlable, sobre la que argumenta Butler, se apoya en la noción de iterabilidad derridiana ${ }^{31}$.

Desde la introducción de Excitable Speech su propósito estriba en ofrecer un acercamiento al lenguaje que permita pensarlo no sólo como sistema sino sobre todo bajo la figura de una agencia que no implica en absoluto la noción de control o de dominio. Una parábola de Toni Morrison le sirve de ilustración: se trata del caso de una mujer ciega a la que unos niños preguntan sobre si está vivo o muerto el pájaro que encierran en sus manos. El pájaro ocupa en Morrison el lugar del lenguaje. Y la respuesta dada por la mujer, que desviando la pregunta dice saber únicamente que el pájaro está en sus manos -en las manos de los niños-, alude para Butler a una concepción del lenguaje como realidad viva. El lenguaje es ahí comprendido como agencia en el sentido de "acto con consecuencias" 32 ; lenguaje es algo que hacemos, una cierta acción característica, y los efectos que producimos.

\section{LA DIMENSIÓN CORPORAL DEL HABLA}

Decir que el habla es un acto no es suficiente. Es una acción cuya peculiaridad es su crucial dimensión corporal. Aquí Butler remite al estudio de Shoshana Felman para quien entre habla y cuerpo se da una relación "escandalosa", una relación de "incongruencia y de inseparabilidad", donde "el escándalo consiste en el hecho de que el acto no puede saber lo que está haciendo"33. Que entre

31 No obstante, en Lenguaje, poder e identidad, Butler tampoco dejará, en algunos aspectos, de someter a revisión la teoría de Derrida. Butler enfrentará críticamente la teoría de Derrida y la del poder social de Bourdieu, pero sus desacuerdos con ambos autores se deben sobre todo a que en su obra el concepto de agencia es central.

32 Judith Butler, Lenguaje, poder e identidad, op. cit., p. 24; Excitable Speech, op. cit., p. 7.

33 Judith Butler, Lenguaje, poder e identidad, op. cit., p. 28; Excitable Speech, op. cit., p. 10. Vuelve Butler a aludir a esta obra de Felman en Deshacer el género, Barcelona, Paidós, 2006 (“¿El fin de la diferencia sexual?”), pp. 281-282; Undoing Gender, Routledge, New York-London, 2004 (“The End of Sexual Difference?"), p. 199, donde afirma que, en general, sigue el punto de vista de la autora de The Scandal of the Speaking Body para quien "los significados del cuerpo exceden las intenciones del sujeto". Pero ello se debe entender no en un sentido metafísico sino en el sentido de que el lenguaje vehicula afirmaciones corporales y acciones que no siempre son comprendidas por quien habla y por quien pretende que su habla exprese intenciones conscientes. Aquello que hacemos con nuestro lenguaje no se corresponde exactamente con los significados que conscientemente queremos comunicar. 
lenguaje y cuerpo hay un íntimo y problemático vínculo que reclama seguir siendo pensado; que materialidad y lenguaje no son la misma cosa pero que estrechan lazos de interdependencia no siendo nunca ni "completamente idénticos ni completamente diferentes", son observaciones presentes en Bodies that Matter y destinadas a indagar en el proceso discursivo -performativo- de materialización del cuerpo. Pero el análisis de Felman centra la cuestión en la espinosa mas evidente conexión entre habla y cuerpo en una dirección que permite a Butler defender, desde una distinta esclarecedora perspectiva -no, esta vez, la de la estructura iterable del lenguaje, hallada, en principio, en la escritura, sino la del habla del cuerpo que habla-, ese rasgo característico de su concepción del lenguaje de una agencia en ausencia de control soberano.

En ese habla que es del cuerpo, el acto de habla, según Felman, no alcanza a conocer por completo aquello que produce mediante su habla; el acto de habla no es, por tanto, capaz de ejercer sobre su intencionalidad un dominio y un control como la mayoría de las veces pretende. El cuerpo del hablante significa no sólo lo que dice su habla. Butler, en este sentido, compara al hablante de Felman, para el que su cuerpo no es totalmente conocido porque sus acciones no son todas voluntarias y conscientes, con aquella mujer ciega de la narración de Morrison ${ }^{34}$. Esos aspectos ciegos, desconocidos, del cuerpo, del habla del cuerpo, señalan el límite de la intencionalidad de un acto de habla que dice más o que dice menos, o en forma distinta, de lo que se propone decir.

La idea fundamental de Felman no es que son realidades independientes habla y cuerpo. Como dirá Butler en su posterior texto "Afterword" 35 , sobre el escrito de Felman, el cuerpo es condición y vehículo del habla. Pensar que el acto de habla transmite la intención del hablante, supone situar la conciencia en un lugar anterior y distinto al habla que entonces queda concebida como un medio que refleja un previo contenido de conciencia. Sin embargo, no es posible prescindir del cuerpo, como elemento orgánico que es del habla; ni tan siquiera puede evitarse el cuerpo cuando el habla pretende comunicar una intención de la conciencia. Felman cuestionando la presuposición de Austin de que el yo del hablante es una conciencia pura cuya intención es correcta y transparentemente representada a través de su lenguaje, nos propone considerar que lo que representa en el lenguaje el yo es su vida corporal. En tal caso, el punto de vista de Felman incide en acentuar una relación entre cuerpo y lenguaje que rompe con la noción de representación sostenida en la tesis metafísica del yo soberano intencional.

34 Judith Butler, Lenguaje, poder e identidad, op. cit., p. 29; Excitable Speech, op. cit., p. 10.

35 Judith Butler, "Afterword", en Shoshana Felman, The Scandal of the Speaking Body. Don Juan With J. L. Austin, or Seduction in Two Languages, op. cit., pp. 115-117. 
Del análisis de Felman retiene Excitable Speech esta puesta en evidencia de que la intencionalidad en el acto de habla queda quebrada por esa dimensión corporal del habla. Las dualidades metafísicas no son sostenidas sino, al contrario, desbaratadas. Este texto cita Butler de Felman: "El acto, una producción enigmática y problemática del cuerpo parlante, destruye desde su comienzo la dicotomía metafísica entre el dominio "mental" y el dominio "físico", desmonta la oposición entre cuerpo y espíritu, entre la materia y el lenguaje" 36 .

No son existencias aisladas las del habla y el cuerpo pero tampoco se vinculan fácil y transparentemente. El cuerpo es el lugar de la verbalización. Pero, además, Felman, apoyándose en la teoría psicoanalítica afirma que el cuerpo es también el lugar del deseo corporal en tanto fantasías inconscientes ${ }^{37}$. En esta línea, entendido como instrumento de lo inconsciente, el cuerpo se mueve en una dirección contraria a la intención consciente; el cuerpo es lo no intencional. Ese yo que en su habla dice su vida corporal no puede, en consecuencia, conocerse a sí mismo por entero. En su acto de habla performativo no acaba nunca de saber exactamente lo que hace porque el suyo no es un yo soberano.

Tal y como se recoge en Excitable Speech, el acto de habla del cuerpo realiza una acción doble: la acción de la enunciación y la acción de lo dicho por el cuerpo. En la amenaza, ejemplifica Butler, puede darse una situación en la que el acto performativo de amenazar se vea debilitado por la actitud del cuerpo emisor de la amenaza; o, por otro lado, puede que la expresión pronunciada no contenga una amenaza desde un análisis gramatical pero que el cuerpo del hablante, su comportamiento, haga irrumpir una amenaza. Ambos actos, aun siendo corporales los dos, no son lo mismo y, sin embargo, están relacionados. A la relación entre uno y otro la denomina Butler quiasmo.

En la amenaza el acto de habla en el que se formula se cumple en cuanto tal acto de habla, pero ese acto de habla de la amenaza anuncia otro acto posterior que será el que pueda o no cumplirse, materializando con ello, o no, el acto de habla de la amenaza. La amenaza en su eficacia es vulnerable; el acto de habla puede fracasar no materializándose. Entendida la amenaza, prosigue Butler, como acto soberano, como acto ilocucionario según la fórmula de Austin, se da por sentado que la amenaza, la enunciación de la amenaza, realiza la acción que dice. Esto discute Butler argumentando que está abierta al fracaso, que hay respuestas imprevistas a la amenaza que impiden concebirla bajo la óptica de un acto de habla que controla netamente lo que dice. La amenaza podría

36 Judith Butler, Lenguaje, poder e identidad, op. cit., p. 29; Excitable Speech, op. cit., p. 11. El texto citado por Butler se encuentra en Shoshana Felman, The Scandal of the Speaking Body. Don Juan With J. L. Austin, or Seduction in Two Languages, op. cit., p. 65.

37 Judith Butler, "Afterword", op. cit., pp. 118-119. 
conllevar antes que la falta de réplica por parte de la persona amenazada una contestación resistente que puede aprovechar esa circunstancia de la doble faz de la amenaza -lo intencional y lo no intencional del habla corporal-.

De ahí que, la amenaza, acto de habla y acto corporal que excede el habla, señala hacia su estar fuera de su propio control. Y de ahí que el habla que hiere, en general, pueda ser observada desde este prisma de "la inseparable incongruencia", como decíamos, entre habla y cuerpo; entre lo dicho y los efectos de lo dicho. Ni el cuerpo del que habla ni tampoco el cuerpo al que se dirige el habla quedan sin más bajo el control del acto de habla.

\section{LOS ACTOS DE HABLA DE CONFESIÓN}

Desde otra perspectiva todavía Butler analiza la difícil relación entre el lenguaje y el cuerpo. En su texto titulado "Bodily Confessions" 38 , indaga en los actos de habla de confesión retomando elementos de Foucault y de la teoría psicoanalítica fundamentalmente.

En su primer volumen de la Historia de la sexualidad se refiere Foucault al poder pastoral ejercido en la confesión cristiana desde la perspectiva ofrecida por su elaboración de la hipótesis represiva. Según ello, se trata en la confesión de descubrir, desvelar mediante el lenguaje, los deseos más ocultos y verdaderos; ofrecerlos al conocimiento del pastor para que por este medio ejerza la función de dirigir y gestionar, de controlar, en definitiva, el alma del confesado. Afirmar la represión del sexo, de los deseos, es ante todo, afirmaba Foucault, un mecanismo de poder que impone revelar aquello supuestamente reprimido, y ya existente, para lograr el aumento del poder de la autoridad pastoral. Butler está interesada en este caso particularmente en la distinta versión del acto de confesión que el propio Foucault proporciona, en su texto posterior de 1980 "About the Beginning of the Hermeneutics of the Self" 39 , cuando interpreta que en la confesión "El yo no es algo que deba ser descubierto o descifrado como una parte muy oscura de nuestro yo" 40 sino que la confesión es una actividad

38 Judith Butler, “Confesiones corporales", en Deshacer el género, op. cit., pp. 229-246; "Bodily Confessions", en Undoing Gender, op. cit., pp. 161-173. Este escrito fue presentado por primera vez en el “American Psychological Division Meetings (Division 39”, en San Francisco y en la primavera de 1999.

39 Este texto de Michel Foucault, "About the Beginning of the Hermeneutics of the Self", fue publicado en Mark Blasius (ed.), Political Theory, vol. 21, n 2, May, 1993, pp. 198-227; y más tarde fue publicado en Jeremy Carrette (ed.), Religion and Culture, New York, Routledge, 1999, pp. 158-181.

40 Judith Butler, "Confesiones corporales", op. cit., p. 231; "Bodily Confessions", op. cit., p. 163. 
en donde mediante el habla el yo se constituye a sí mismo ante la presencia propiciadora de otra persona. Queda destacada bajo esta luz la fuerza performativa de la enunciación.

En el psicoanálisis pervive de alguna manera ese poder pastoral. De lo que se trata no sólo es de que ha sido hecho un acto sino que sucede que ese acto es narrado y que al ser verbalizado el hecho ha sido alterado en cierto sentido. El cuerpo que ha realizado el hecho actúa otra vez en el acto corporal que supone la confesión del hecho. A través del acto de habla es cuando el hecho y el sujeto del hecho y del habla son vulnerables y se hallan abiertos a su reinterpretación. Recurriendo a la Antígona de Sófocles, Butler afirma que es su acto en el lenguaje, su confesión, con la que da publicidad al acto de haber enterrado a su hermano, ante Creonte -quien, como si dijéramos, ocupa el lugar del psicoanalista-, lo que supone de algún modo la terminación del hecho. Antígona desafía a Creonte al no cumplir su edicto; y al rechazar verbalmente negar que ella ha enterrado a su hermano desobedece de nuevo a Creonte. Ella reitera su acto de insubordinación por vía de su declaración lingüística.

La escena de la confesión, en toda su complejidad, también pone en evidencia, por tanto, el carácter excesivo del acto de habla. Excesivo porque el habla otorga al hecho una otra dimensión. Pero, además, porque las intenciones, tanto de la persona que se analiza como asimismo de quien ejerce de psicoanalista, pueden ser confundidas en el transcurso de la comunicación; siempre permanece el riesgo de hacer algo que no sea lo que se haya pretendido hacer. La atención, frecuente en el modo de la escucha del psicoanalista, del aspecto retórico del lenguaje, de las palabras elegidas o del ritmo de la verbalización, por ejemplo, pueden provocar comentarios no bien recibidos por parte del emisor del habla, este que está sometiéndose a la terapia, a quien le preocupa sobre todo el contenido de su enunciación. Butler incide en cómo en la terapia puede darse relevancia a significados que no necesariamente tienen que ver con el contenido de lo que se dice. Puntualiza, no obstante, que el contenido no puede ser completamente transcendido ya que el modo de la enunciación es con probabilidad un aspecto vinculado con el contenido y con su intención. Entonces, la cuestión que debe ser destacada es que, a pesar de las divergencias, hay una cierta unidad en la conversación constituida por el significado intencional y por el efecto no intencional del habla ${ }^{41}$.

Por otra parte, en "Bodily Confessions" Butler destaca también este exceso del lenguaje insistiendo de nuevo en la esfera corporal del acto de habla. La "laringe", los "pulmones", los "labios", la "boca", son condiciones de la voca-

41 Judith Butler, "Confesiones corporales", op. cit., p. 243; "Bodily Confessions", op. cit., p. 172. 
lización, afirma Butler ${ }^{42}$. El cuerpo, sin duda, está presente en la situación del habla. Incluso cuando parece quedar obstruido el cuerpo en un habla que pretende transmitir significados descorporalizados, como emanados de una mente sin cuerpo que se dirige a otra mente desencarnada, incluso entonces, ese habla no puede evitar su relación con el cuerpo en tanto habla descorporalizada.

Un extraño ofrecimiento corporal son las palabras habladas ${ }^{43}$. En la terapia, continúa su argumentación, se despliega algo más que una intención. A la opinión relatada acompaña una mostración de una parte de sí desconocida para el propio sujeto del habla. Al exponerla la entregamos a la otra persona con el fin de que nos la devuelva de una manera tal que es imposible de prever por anticipado. Ese yo que habla en el transcurso de la conversación se reelabora en nuevos y diferentes caminos. Butler apunta que en estas escenas de habla aquello que ambos intervinientes enuncian se extiende "más allá de su control (beyond their control)", sin embargo no por ello su decir está "fuera de control (out of control)" "44. Sabemos que el habla es una forma de hacer algo. Lo que hace el habla tiene que ver en alguna medida con el yo; el yo que se va rehaciendo mediante el habla y en el habla. Por lo tanto, es la conversación un decir y un hacer algo juntos en donde es posible una modificación de los sujetos aunque lo que ahí se cumpla no pueda ser conocido hasta que suceda ${ }^{45}$.

Este es el sentido en el que nuestra habla no permanece encerrada exhaustivamente bajo nuestro control. Y es también el sentido en el que nuestra habla no nos es completamente ajena porque en el desarrollo de la misma nos vamos

42 Judith Butler, "Confesiones corporales", op. cit., p. 243; "Bodily Confessions", op. cit., p. 172.

43 Judith Butler, "Confesiones corporales", op. cit., pp. 244-245; "Bodily Confessions", op. cit., p. 172.

44 Judith Butler, "Confesiones corporales", op. cit., p. 246; "Bodily Confessions", op. cit., p. 173. El texto original dice así: "In these scenes of speech, both interlocutors find that what they say is to some extent beyond their control but not, for that reason, out of control". Sin embargo, la traducción castellana no recoge el texto completo de Butler, con lo que se pierde parte del sentido de lo escrito: "En estas escenas del habla, ambos interlocutores se dan cuenta de que, hasta cierto punto, lo que dicen está fuera de control".

45 En otro contexto y desde otra perspectiva, Butler subraya esta idea: la posibilidad, y todavía más, la conveniencia, de que en el intercambio comunicativo se produzca una modificación de las personas implicadas, de sus puntos de vista, de sus certezas y seguridades conceptuales y vitales. En su texto "La cuestión de la transformación social", en Judith Butler, Elisabeth BeckGernsheim y Lídia Puigvert, Mujeres y transformaciones sociales, Barcelona, El Roure, 2001, pp. 7-30 (El texto también está en Deshacer el género, op. cit., pp. 289-327; Undoing Gender, op. cit., pp. 204-231), llama a esta conversación transformadora una tarea de "traducción cultural". En la traducción cultural la transformación se produce a través de un encuentro con lo otro, con lo desconocido, en el que las dos partes se modifican. Es así como Butler comprende el poder fructífero del diálogo. 
haciendo a nosotros mismos. Aunque aquí Butler no lo enuncia explícitamente, no deja de estar apuntando hacia esa agencia -capacidad de acción- que emerge en el devenir del ejercicio lingüístico; en el diversificado movimiento del lenguaje; "excitable", "excesivo" lenguaje.

Es, justamente, en la posibilidad del fracaso donde el lenguaje, lenguaje performativo, abre el espacio para la agencia del sujeto: "Este fracaso constitutivo de lo performativo, este deslizamiento entre el mandato discursivo y su efecto apropiado es lo que proporciona la ocasión y el índice lingüísticos de la desobediencia resultante" 46 . El lenguaje no es el espacio donde reside un poder soberano pero abierto como está, desde la teoría de Butler, a la resignificación subversiva, es donde acontece la capacidad de acción del sujeto. Un sujeto que es un cuerpo que actúa en buena medida mediante su habla. 
